\title{
Design and Implementation of dsPIC Fed Vienna Rectifier for Induction Heating Appliances
}

\author{
S.Manojmanimaran \\ PG Student \\ Department of EEE \\ Rajalakshmi Engineering College
}

\author{
C. Amutha \\ Assistant professor \\ Department of EEE \\ Rajalakshmi Engineering College
}

\begin{abstract}
The main work of this paper is to increase the efficiency and also safe operation of the power electronics switches which are used in the circuit. Induction heating is a technique, in that a suitable range of frequencies is needed for different work piece geometry requirements. More number of topologies is available among which half bridge topology is found to be efficient. The approach is based on the closed loop operation in order to improve the efficiency of the induction heating system. This project describes the main consideration in the study of resonant converter, PID controller and VIENNA rectifier for an induction heating appliances. Here the controller used is dsPIC (digital signal controller) for producing switching pulses to the inverter section and Vienna rectifier. The simulation is obtained using MATLAB/SIMULINK.
\end{abstract}

\section{Keywords}

PWM, PID ,dsPIC, MPLAB IDE, MATLAB/SIMULINK

\section{INTRODUCTION}

Induction heating appliances are widely used due to improvement in power electronics devices and digital control system[1]-[6]. It is more desirable due to its fastest heating time and efficiency. The principle of operation is based on the generation of a variable magnetic field by means of a planar inductor below a metallic vessel. The main voltage is rectified and after that an inverter provides a medium-frequency current to feed the inductor. The operating frequency of the switch should be higher than $15 \mathrm{KHz}$ and lower than $70 \mathrm{KHz}$ in order to reduces the switching losses and also safe operation of power electronics devices.

Several resonant inverter architectures have been applied to domestic heating applications: half bridge, full-bridge, SWZVS, SW-ZCS inverter topologies[9].Among them, the halfbridge series resonant converter is the most used topology due to its good balance between the cost and performance[11][12]. The most common topologies which is used in power electronics circuit is half-bridge configuration.

The digital signal Peripheral Interface Controller is used for the implementation of the Vienna rectifier and inverter section. dsPIC controller is coded with the help of the software MPLAB to get the PWM pulses which are the input for the converter part. In the closed loop system, the feedback signal is given as the input to the PID controller (Proportional Integral Derivative). PID controller is tunned by using
ZIEGLER - NICHOLS method (Z-N). Thus, the PID controller tunes the value and gives a stabilized output. The controller has a separate PWM port, which provides ease of operation. The coding is compiled and debugged and loaded into the controller. Here, dsPIC $30 \mathrm{~F} 4011$ is compiled using MPLAB software and loaded into hardware using WINPIC 800.

\section{SYSTEM MODEL}

The following Fig 1 shows the block diagram of dsPIC based induction heating system

\subsection{Power Supply Unit}

Induction Heating (IH) has become the technology of choice for domestic applications due to its advantages such as efficiency, fast heating, quickness, safety and accurate power controls[2][3]

The user selects the desired power level through the user interface. Then, the IH cooktop has to perform accurate and smooth power control in order to supply the desired power level to the vessel. The energy conversion block diagram of a dsPIC based induction heating system is shown in Fig1. F irst an electromagnetic compatibility filter is included in order to fulfill the EMC regulations. Next, a rectifier and a filter convert the ac mains voltage to a dc bus. Finally, the inverter stage converts the bus voltage into a medium-frequency ac current that flows through the inductor coil heating up the vessel. The rectifier and inverter part is the important to design in order to increase the efficiency and better performance.

\subsection{Vienna Rectifier}

The Vienna rectifier circuit is the combination of a half bridge rectifier and boost converter[7][8]. The AC supply is rectified using the Diodes. During the positive half cycle the diode $\mathrm{D}_{\text {ap }}$ is in the ON state and during the negative half cycle the diode $\mathrm{D}_{a n}$ is in the ON state. Based on the Duty cycle to the bidirectional switch the boost output is controlled.

\subsection{Half-Bridge Inverter Topology}

Several resonant inverter architectures have been applied to domestic induction heating applications: half bridge, fullbridge, SW-ZVS , SW-ZCS inverter topologies[9]. Among them, the half-bridge series resonant converter is the most used topology due to its good balance between the cost and performance[11][12]. 


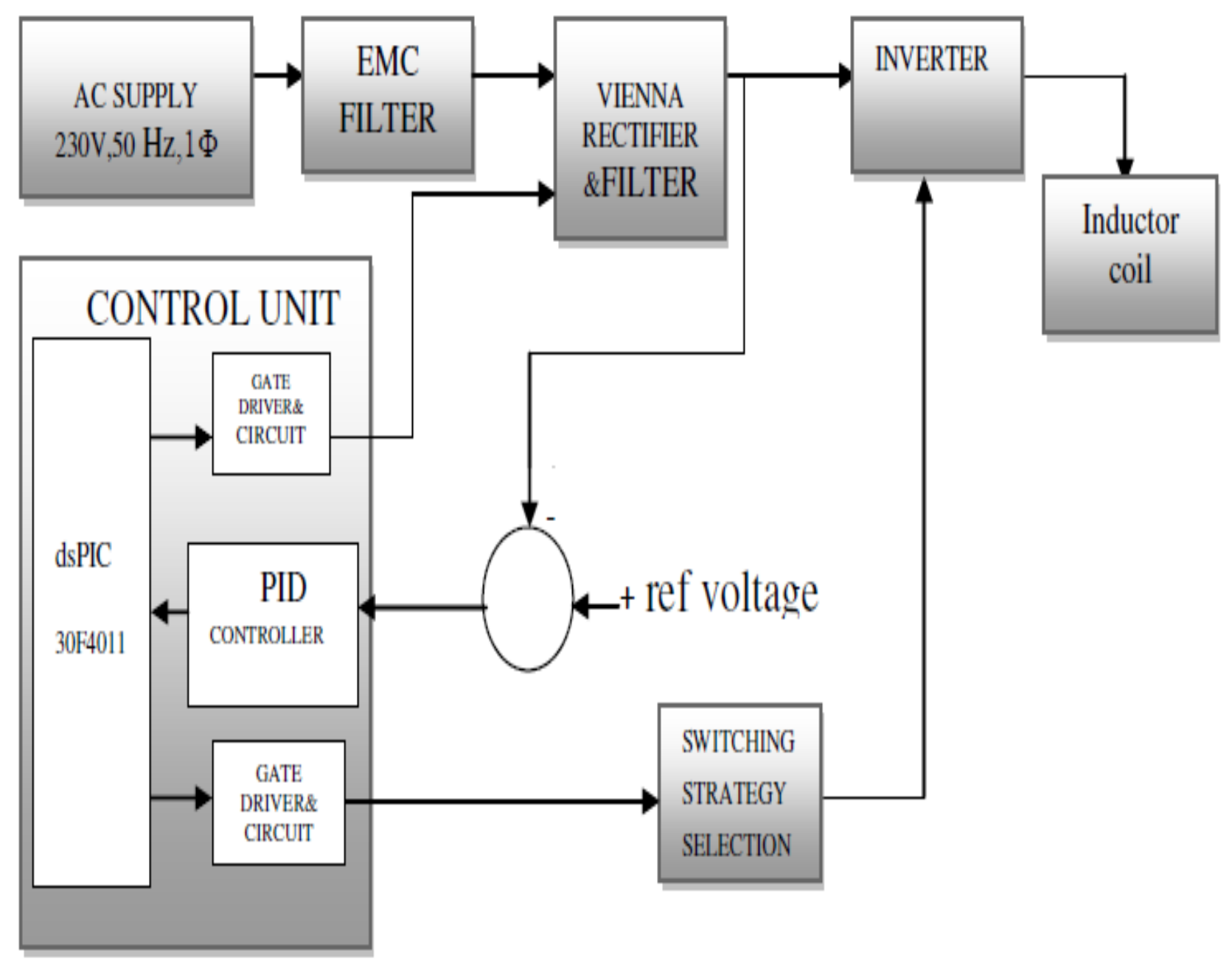

Fig 1: Block diagram of dsPIC based induction heating System

The topologies is used in various applications such as buck converters, resonant converters, motion control and induction heating and also offers such benefits as zero-voltage switching (ZVS)[11], high efficiency, low EMI and high-frequency operation.

\section{THEORETICAL VERIFICATION}

The system uses the PID controller, which helps in tuning the system. The output of the system is taken as feedback and compared with the reference signal.

The PID controller produces an output signal consisting of three terms, they are

\section{- Proportional to error signal.}

- Proportional to integral of error signal.

- Proportional to derivative of error signal

In PID controller, the first order transfer function is,

$\frac{\mathrm{U}(\mathrm{s})}{\mathrm{E}(\mathrm{s})}=\mathrm{k}_{\mathrm{p}}+\frac{\mathrm{k}_{\mathrm{i}}}{\mathrm{s}}+\mathrm{k}_{\mathrm{d}} \mathrm{s}$

By applying the $\mathrm{k}_{\mathrm{p}}, \mathrm{k}_{\mathrm{i}}$ and $\mathrm{k}_{\mathrm{d}}$ values to the above equations, $\frac{2.934 \mathrm{~s}^{2}+3.345 \mathrm{~s}+0.0029}{\mathrm{~s}}$

$$
\frac{\mathrm{U}(\mathrm{s})}{\mathrm{E}(\mathrm{s})}=\frac{2.934 \mathrm{~s}^{2}+3.345 \mathrm{~s}+0.0029}{\mathrm{~s}}
$$

The closed loop transfer function is,

$$
\frac{\mathrm{C}(\mathrm{s})}{\mathrm{R}(\mathrm{s})}=\frac{\mathrm{G}(\mathrm{s})}{1+\mathrm{G}(\mathrm{s})}
$$

The second order transfer function order is given as,

$$
\frac{\mathrm{C}(\mathrm{s})}{\mathrm{R}(\mathrm{s})}=\frac{\omega_{\mathrm{n}}^{2}}{\mathrm{~s}^{2}+2 \varepsilon \omega_{\mathrm{n}} \mathrm{s}+\omega_{\mathrm{n}}^{2}}
$$

\subsection{Ziegler - Nichols Method}

The Ziegler - Nichols (Z-N) method is a heuristic method of tuning PID controller. First the integral (I) and derivative (D) is set to zero. And proportional gain $(\mathrm{P})$ is varied until it reaches the ultimate gain or critical gain. This tuning rule (Trial and Error method) is meant to give PID loops best disturbance rejection. By using this tuning rule the values for $\mathrm{K}_{\mathrm{p}}, \mathrm{K}_{\mathrm{i}}$ and $\mathrm{K}_{\mathrm{d}}$ are determined as shown in, TABLE 1.

TABLE 1: Ziegler - Nichols method Values

\begin{tabular}{|l|l|l|l|}
\hline $\begin{array}{l}\text { CONTROL } \\
\text { TYPE }\end{array}$ & $\mathrm{K}_{\mathrm{p}}$ & $\mathrm{K}_{\mathrm{i}}$ & $\mathrm{K}_{\mathrm{d}}$ \\
\hline VALUE & 2.934 & 3.345 & 0.0029 \\
& & & \\
\hline
\end{tabular}




\subsection{Closed loop Vienna rectifier - proposed

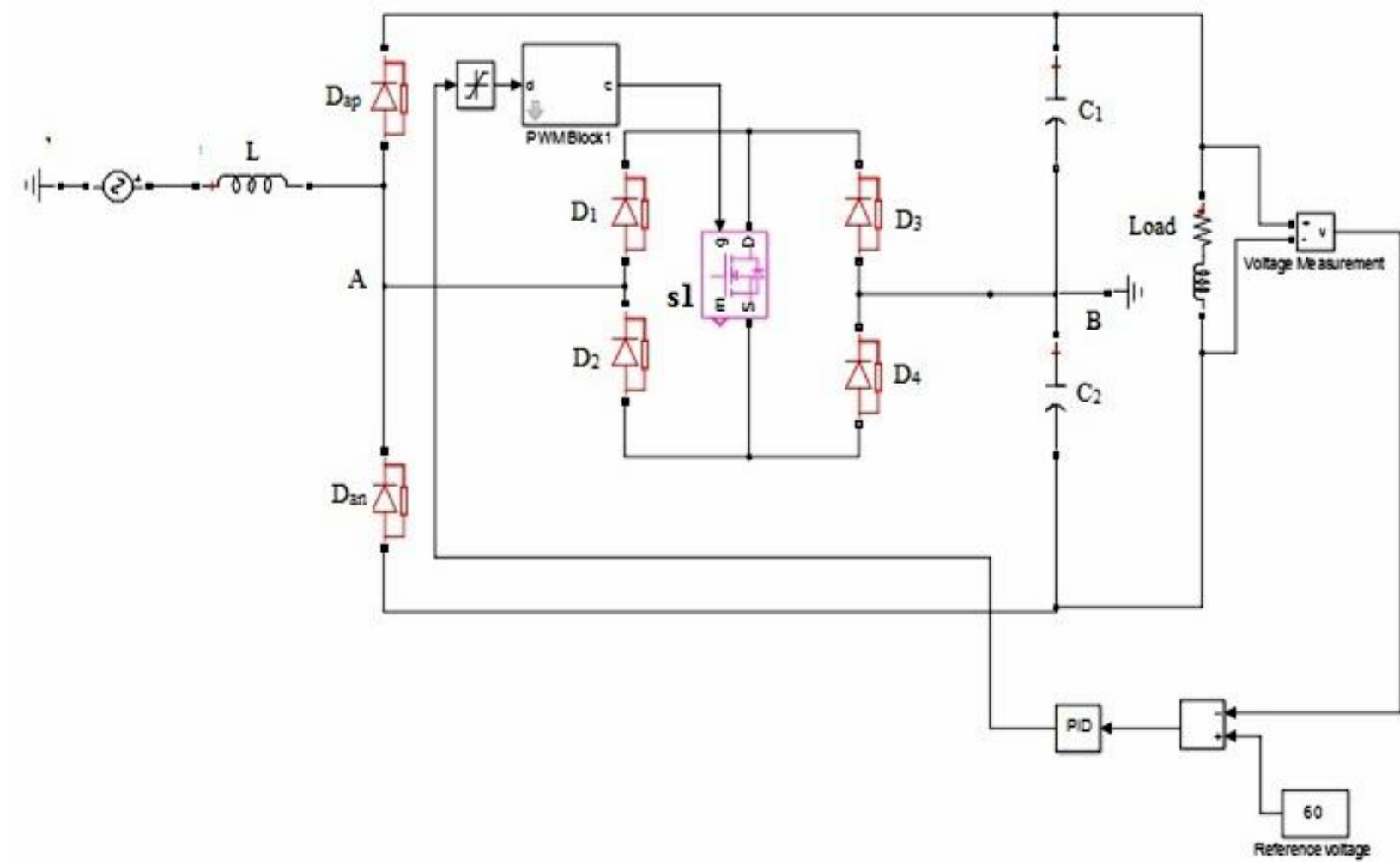

Fig 2 : Closed loop vienna rectifier

The Fig 2 shows the closed loop vienna rectifier. A Vienna rectifier circuit is the combination of a half bridge rectifier and boost converter[7][8]. The AC supply is rectified using the Diodes .During the positive the diode $\mathrm{D}_{\mathrm{ap}}$ is in the ON state and during the negative cycle the diode $\mathrm{D}_{\mathrm{an}}$ is in the $\mathrm{ON}$ state.

$$
\text { PARAMETERS : } \mathrm{L}, \mathrm{C}_{1}, \mathrm{C}_{2}
$$$$
\mathrm{I} / \mathrm{P} \text { voltage }=24 \mathrm{~V}
$$

The voltage drop across the inductor limited to $10 \%$

Therefore, input voltage $=2.4 \mathrm{~V}$

In order to calculate the $\mathrm{L}$ value,

$$
\begin{aligned}
& \text { GLI = V } \\
& \begin{array}{l}
\mathrm{V}=\mathrm{IR} \\
\mathrm{I}=\mathrm{V} / \mathrm{R} \\
\mathrm{I}=24 / 100 \\
\mathrm{~L}=? \\
\mathrm{G}=2 \Pi \mathrm{f} \\
\mathrm{f}=50 \mathrm{~Hz} \\
\mathrm{~L}=\mathrm{V} / 2 \Pi \mathrm{H} * \mathrm{I} \\
\mathrm{L}=31 \mathrm{mH}
\end{array}
\end{aligned}
$$

In order to calculate for $C_{1}, C_{2}$

$$
\begin{aligned}
& C_{1}=I_{o} / V_{c}{ }^{*} f \\
& I_{0}=2.499 A \\
& C_{1}=2200 * 10^{-6} \mathrm{~F}
\end{aligned}
$$

$$
\begin{aligned}
& \mathrm{C}_{1}=2200 \mu \mathrm{F} \\
& \mathrm{C}_{2}=\mathrm{I}_{\mathrm{o}} / \mathrm{V}_{\mathrm{c}}{ }_{\mathrm{f}} \\
& \mathrm{I}_{\mathrm{o}}=2.499 \mathrm{~A} \\
& \mathrm{C}_{2}=2200 * 10^{-6} \mathrm{~F} \\
& \mathrm{C}_{2}=2200 \mu \mathrm{F}
\end{aligned}
$$

\section{SIMULATION RESULTS}

In this section, the simulation result of induction heating system using Vienna rectifier, half bridge inverter, PID controller is presented. The output waveform of power for closed loop system is shown. The performance of switching action in converter depends on the active and passive switch. The active switch is directly controlled for an external control signal. It is usually implemented with a bipolar or a fieldeffect transistor.

For the closed loop system, the values obtained in PID controller by using the Z-N method are determined. The error signal is compared with reference signal and fed to PID controller, and values are determined. The waveform from relational operator is given as input to the IGBT (INSULATED-GATE BIPOLAR TRANSISTOR). IGBT acts as a switch.

The Fig 3 describes the closed loop system for induction heating system is shown in which the AC supply is provided to rectifier part and the output DC voltage is provided to the inverter section. In which the inverter section is a half bridge inverter circuit that converts dc voltage to ac voltage, because ac voltage is provided to inductor system for quick heating process. 


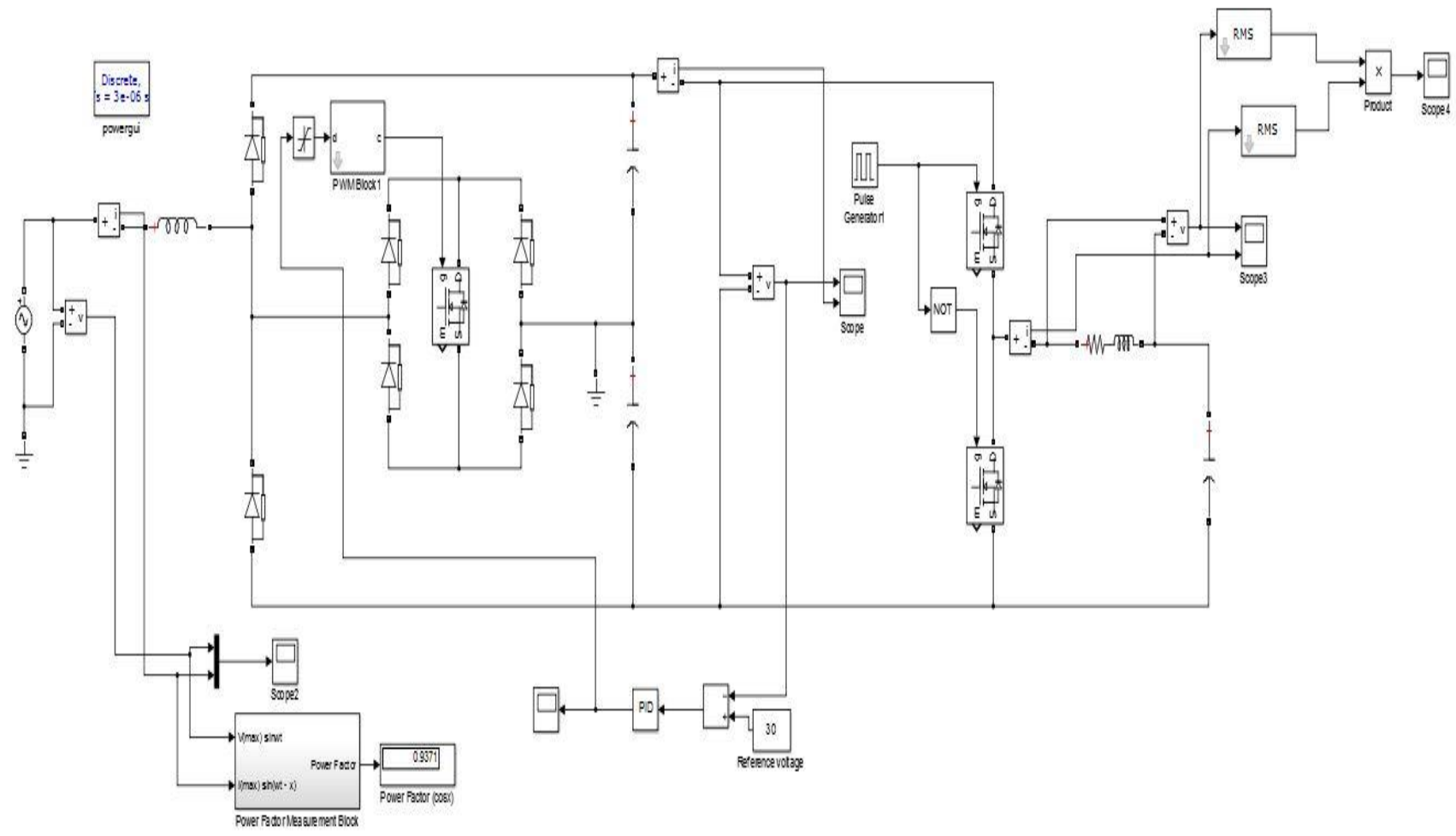

Fig 3: Simulation model of Induction Heating system

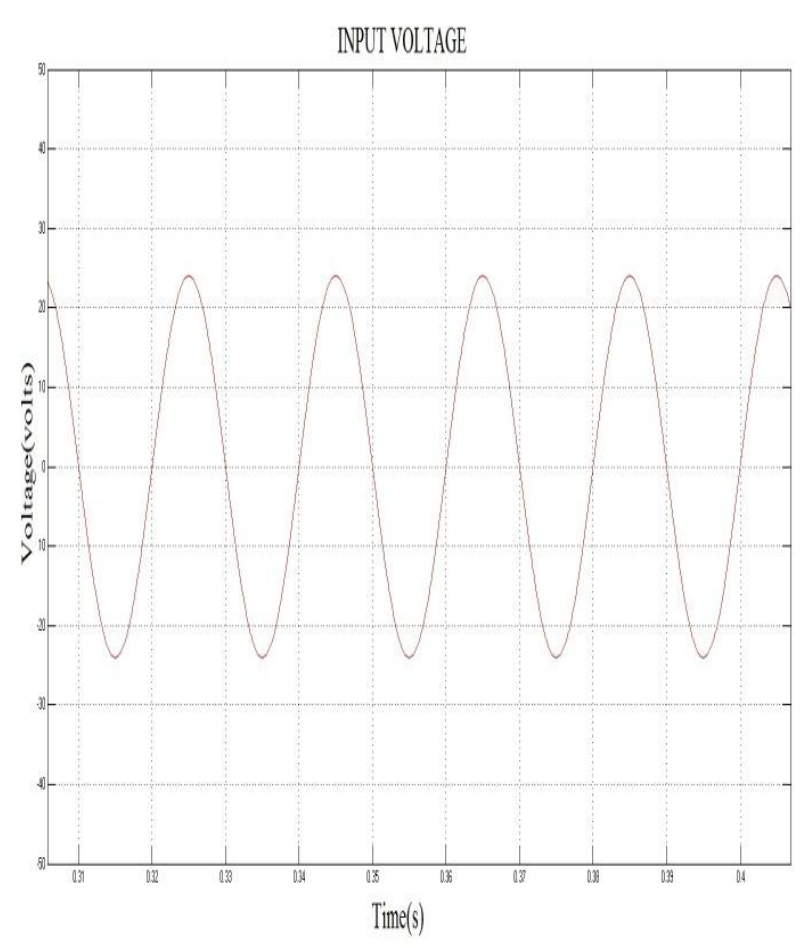

Fig 4: Input voltage waveform for induction heating system

The input voltage given to the induction heating system is 24V.The Fig 4 shows the input voltage waveform.

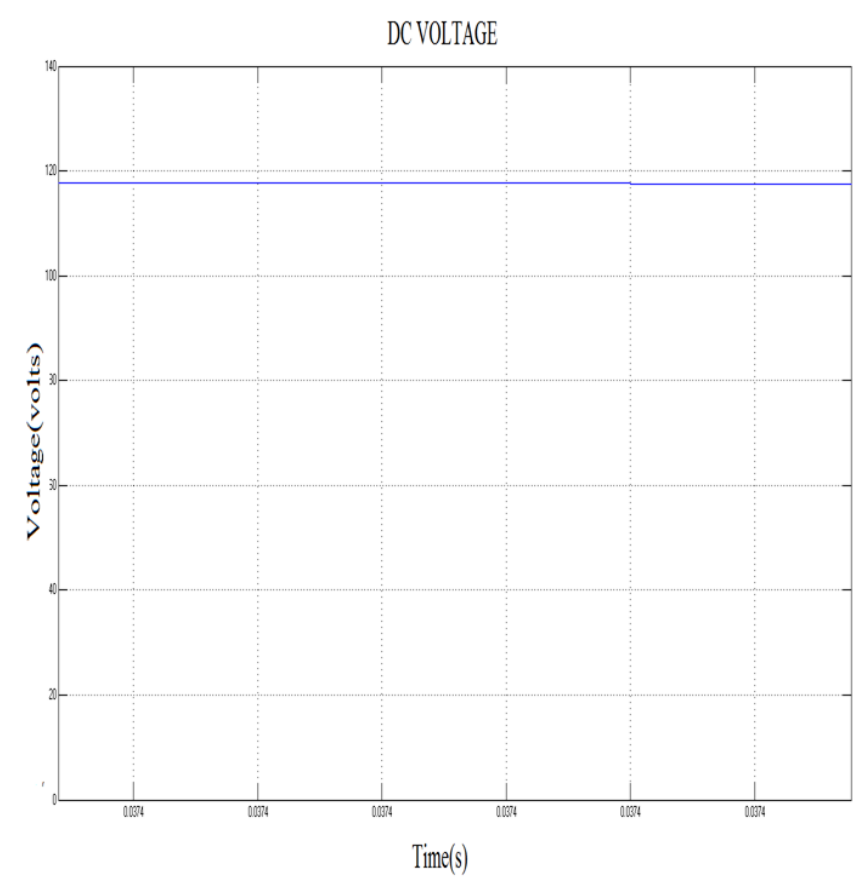

Fig 5: Simulation result for Vienna rectifier

Since the Vienna rectifier circuit is the combination of a half bridge rectifier and boost converter. The given input voltage $24 \mathrm{~V}$ get boosted to $119 \mathrm{~V}$. Fig 4 shows the output voltage waveform for closed loop Vienna rectifier. From graph the output voltage is inferred to be $119 \mathrm{~V}$. 

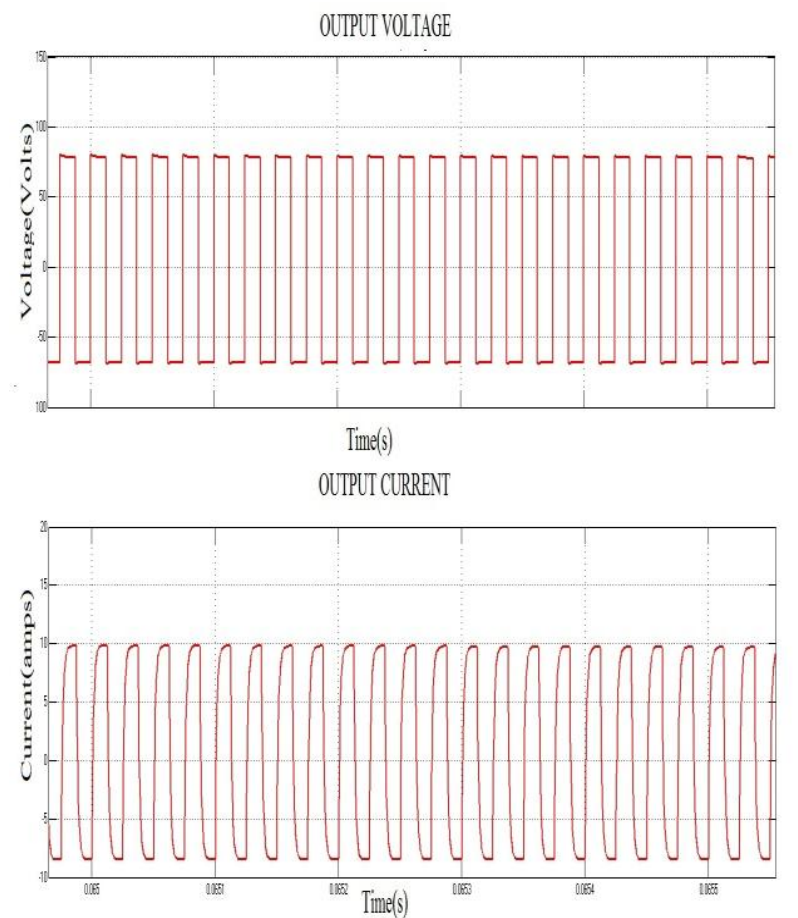

Fig 6 : Output voltage and current waveform for induction heating system

The above Fig 6 shows the simulation result of output voltage and current waveform for induction heating system. The output voltage and current waveform is found to be $65 \mathrm{~V}$ and 7.4 Amps.

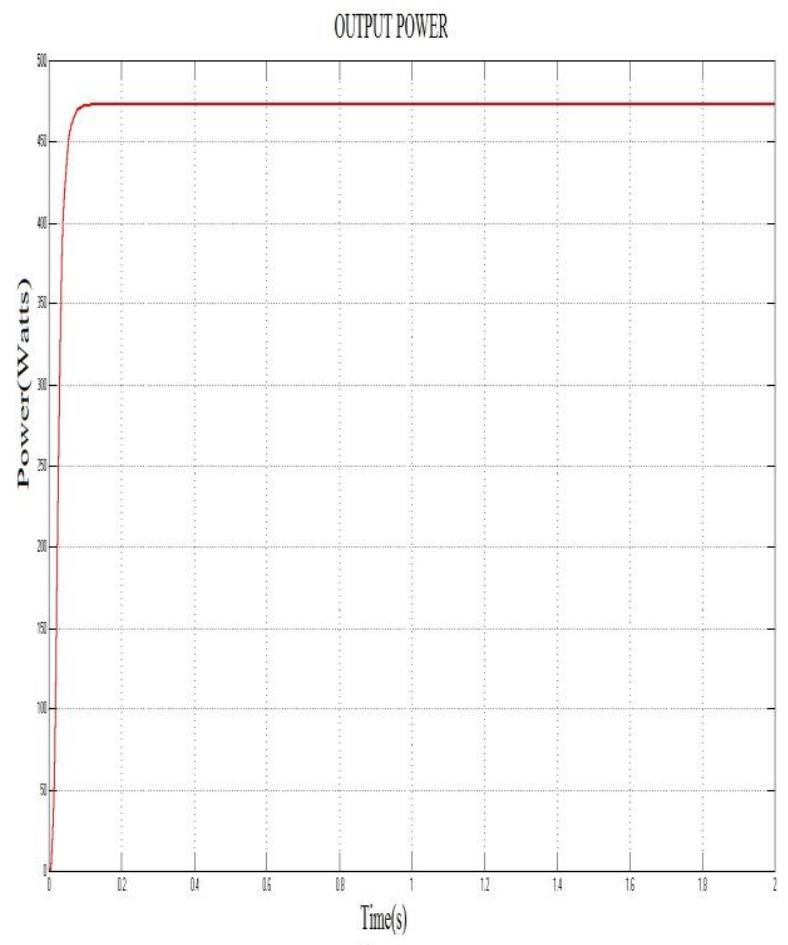

Fig 7: Output power waveform of Induction heating system model.

The above Fig 7 shows the output power waveform. From the graph the output is found to be 480 Watts. The input voltage provided is $24 \mathrm{~V}$.and output achieved is 480 Watts.
Table 2 : Specifications for induction system model

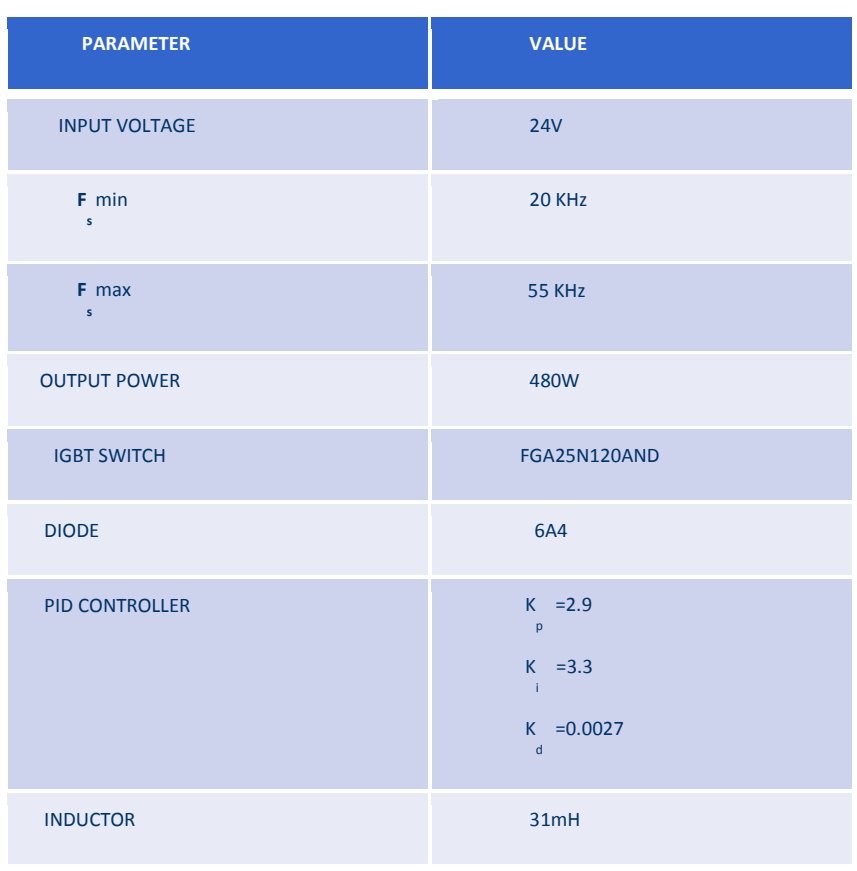

The Table 2 shows the specification and parameter values for induction heating system model.

\section{CONCLUSION}

Thus the analysis for closed loop system is simulated in MATLAB/SIMULINK software tool. From the simulation results, the proposed system using Vienna rectifier and half bridge inverter topology increases the output power and efficiency. The simulation block diagram and the working principle of the induction heating system is discussed and analyzed. In the proposed induction heating system the output power is achieved to 480 Watts and efficiency is also improved.

\section{REFERENCES}

[1] S.Shanthi, et al., Dec. 2013 " Design And Implementation of Low-Cost Power Efficient Embedded Control Systems in Domestic Induction Heating Appliances," IJETAE. Vol. 3, Issue 12, December 2013, pp. $577-582$.

[2] Acero.J, et al., Mar./Apr. 2010 "Domestic induction appliances," IEEE Ind. Appl. Mag.,vol. 16, no. 2, pp. 3947.

[3] Oscar Jimenez, Oscar Lucia, Isidro Urriza, Luis A. Barragan, Paolo Mattavelli,Dushan Boroyevich., "FPGAbased gain-scheduled controller for resonant converters applied to induction cooktops," IEEE Transactions on Power Electronics , Vol. 29, no. 4, pp. 2143-2152,April 2014.

[4] I.Yilmaz, M. Ermis, and I.Cadirci, "Medium-frequency induction melting furnace as a load on the power system," IEEE Trans. Ind. Appl., vol. 48, no. 4, pp. 1203-1214, Jul./Aug. 2012.

[5] H. Sarnago, A. Mediano, and O. Luc'1a, "High efficiency AC-AC power electronic converter applied to domestic induction heating," IEEE Trans.Power Electron., vol. 27, no. 8, pp. 3676-3684, Aug. 2012. 
[6] J. Egalon, S. Caux, P. Maussion, M. Souley, and O. Pateau, "Multiphase system for metal disc induction heating: modeling and RMS current control,"IEEE Trans. Ind. Appl., vol. 48, no. 5, pp. 1692-1699, Sep./Oct. 2012

[7] Wang Linbing, Zhang Chao, "Study of single-phase three level power factor correcting converter," Power Electronics, 2006,40(2):15-19.(in Chinese)

[8] Zhang Xianjin, Fan Caihong, et al.," Research on 3Phase 4-Wire VIENNA Rectifier Based on One Cycle Control,"2012 Fifth International Conference on Intelligent Computation Technology and Automation". 2012, pp. 280- 282 .

[9] S. Llorente, F. Monterde, J.M. Burdío, and J. Acero, “A Comparative Study of Resonant Inverter Topologies Used in Induction Cookers.," IEEE, pp. 1168-1174, 2002.

[10] F.P. Dawson and Praveen Jain, "System for Induction Heating and Melting Applications, a comparison of Load Commuted Inverter" in IEEE Power Electronics Specialist Conf. Rec 1990, pp. 281-290.

[11] O. Luc'1a, J. M. Burd'10, I.Mill'an, J.Acero, and L. A. Barrag'an, "Efficiency oriented design of ZVS half- bridge series resonant inverter with variable frequency duty cycle control," IEEE Trans. Power Electron., vol. 25, no. 7, pp. 1671-1674, Jul. 2010.

[12] A. Fujita, H. Sadakata, I. Hirota, H. Omori, and M. Nakaoka, "Latest developments of high-frequency series load resonant inverter type builtin cooktops for induction heated all metallic appliances," in Proc. IEEE Power Electron. Motion Control Conf., 2009, pp. 2537-2544.

[13] H. Sarnago, O. Luc'1a, A. Mediano, and J. M. Burd'1o, "Class-D/DE dualmode- operation resonant converter for improved-efficiency domestic induction heating system," IEEE Trans. Power Electron., vol. 28, no. 3, pp. 12741285,2013

[14] H. Sarnago, O. Luc'ia, A. Mediano, and J. M. Burd'1o, "Modulation scheme for improved operation of a RBIGBT based resonant inverter applied to domestic induction heating," IEEE Trans. Ind.l Electron., vol. 60, no. 5,pp. 2066-2073, May 2013.

[15] Co, Tomas; Michigan Technological University (February 13, 2004). "Ziegler-Nichols Closed Loop Tuning". Retrieved 2007-06-24 